\title{
Stromal and epithelial cells react differentially to c-kit in fibroepithelial tumors of the breast
}

\author{
ANGELA F. LOGULLO ${ }^{1}$, SUELY NONOGAKI ${ }^{2}$, MARIA DO SOCORRO MACIEL ${ }^{4}$, \\ MÁRIO MOURÃO-NETO ${ }^{4}$ and FERNANDO AUGUSTO SOARES ${ }^{3}$ \\ ${ }^{1}$ Department of Pathology, Universidade Federal de São Paulo - Escola Paulista de Medicina (Unifesp-EPM); \\ ${ }^{2}$ Department of Pathology, Adolfo Lutz Laboratory; Departments of ${ }^{3}$ Pathology, and \\ ${ }^{4}$ Mastology, Hospital A.C Camargo - Hospital do Câncer, São Paulo, Brazil
}

Received June 25, 2008; Accepted August 29, 2008

DOI: 10.3892/mmr_00000041

\begin{abstract}
The CD117 protein is a tyrosine-kinase receptor encoded by the c-kit gene that frequently bears activating mutations in gastrointestinal tumors. Conflicting findings regarding CD117 expression in other stromal tumors, including phyllodes tumors (PTs), have been reported in the literature. The purpose of this study was to evaluate c-kit expression in the stroma and epithelia of fibroepithelial breast tumors and its correlation with clinical pathological variables. Ninety-six fibroepithelial tumors of the breast, including 14 fibroadenomas (FAs), 12 juvenile FAs and 70 PTs, were classified according to stromal cellularity, atypia, epithelial hyperplasia, mitosis and borders into 45 benign (PTB), 17 borderline (PTBL) and 8 malignant (PTM) tumors. CD117 expression was identified in the stromal component in only two cases of PTBL. Overall, 38 cases (39.6\%) showed positive CD117 in the epithelial component, including 20 FAs (10 regular, 10 juvenile) and 18 PTs (11 PTBs and 8 PTBLs). Other cases, including all PTMs, 6 FAs (4 regular, 2 juvenile), 34 PTBs and 10 PTBLs, showed no positivity in the epithelial component. Expression of c-kit did not correlate with diagnosis or malignancy ( $p>0.05$ ). In conclusion, c-kit is expressed more often in the epithelial than in the stromal component in fibroepithelial tumors of the breast, and is associated with benign lesions.
\end{abstract}

\section{Introduction}

Fibroepithelial tumors of the breast are essentially comprised of fibroadenomas (FAs) and phyllodes tumors (PTs) (1). FAs are the most common type, constituting a benign entity formed

Correspondence to: Dr Angela F. Logullo, Universidade Federal de São Paulo - Escola Paulista de Medicina (Unifesp-EPM), Rua Botucatu 746, CEP 04023-062 São Paulo (SP), Brazil

E-mail: aflw@terra.com.br

Key words: proto-oncogene protein c-kit, phyllodes tumor, fibroepithelial neoplasms, breast neoplasms, immunohistochemistry by stromal overgrowth with an epithelial component from the terminal duct. They usually affect younger women 20-35 years of age, but remain stable over decades and grow slowly. In younger patients, they present larger sizes and faster overgrowth, and usually have a peculiar morphology. These are termed juvenile FAs (2).

PTs occur much less frequently $(0.3-0.5 \%$ of all breast lesions) and may be morphologically classified as benign (PTB), borderline (PTBL) or malignant (PTM) (3). Although most cases can be successfully treated by surgical excision, recurrence is a common event, and distant metastasis is associated with the malignant subtype (4). Identification of possible predictive markers of tumor biology that could predict recurrence or metastasis would be useful for the improved treatment of PT. Evidence of an association between markers such as p53 overexpression $(5,6)$ and cell proliferation with histological tumor grade does not add prognostic significance to clinical outcome (7-9).

Previously, the c-kit protein (or KIT receptor tyrosine kinase) was associated with gastrointestinal tumors (GISTs), another type of human fibrous stromal tumor with variable behavior $(10,11)$. Activating mutations in the KIT gene lead to overexpression of the protein occurring in approximately $90 \%$ of GISTs (12). Activation of the receptor's tyrosine kinase activity when the overexpressed c-kit protein binds to its specific ligand, stem cell factor, is associated with cellular proliferation (13). Moreover, mutations in c-kit may stimulate tumor growth via anti-apoptotic signals. The use of STI571 (imatinib), a specific chemotherapeutic agent which has the ability to inhibit tyrosine-kinase activity, has resulted in a much improved response to chemotherapy in GIST (14).

The normal mammary epithelium highly expresses c-kit $(15,16)$. Studies employing different methodologies have led to conflicting results regarding c-kit expression in epithelialderived breast cancer $(17,18)$. Malignant transformation seems to be accompanied by the progressive loss of c-kit activity (19). However, the relatively low prevalence of KIT expression in epithelial-derived neoplasms does not sustain this hypothesis.

Breast cancer could be a promising candidate for STI571 therapy because of its high heterogeneity, with fibroepithelial tumors being the most attractive target. The stromal and epithelial components of these tumors have been reported to 
suffer distinct molecular alterations during carcinogenesis (16). Evaluation of c-kit expression should therefore be conducted specifically and separately in the two components.

Few studies report c-kit overexpression in FAs, and results in PTs remain controversial $(20,21)$. Moreover, the localization of c-kit expression remains unclear. Consequently, in this study, c-kit immunohistochemical expression was evaluated in a series of 96 fibroepithelial breast tumors, with a focus on the stromal component. The correlation of its expression with clinical pathological variables was also determined.

\section{Materials and methods}

Patients. After pathological review, 96 breast tumor cases with adequate specimens were included. The age of the patients ranged between 18 and 83 years, with a median age of 48.7 years. In most cases, the presence of a lump in the breast was the first symptom; in two thirds of cases a mammogram or ultrasound examination had been performed. All cases were reviewed, and tumor classification was confirmed according to diagnostic criteria (mitotic activity, stromal cellularity, nuclear atypia and stromal overgrowth) (3). Tumor width varied from 1 to $25 \mathrm{~cm}$. All cases were treated surgically: a local excision was performed in cases of FA and PTB, and mastectomy was performed in PTBL and PTM cases. Recurrence occurred in three patients, and one patient with PTM died of pulmonary metastasis. All other patients were alive after 5 years of follow-up.

Immunohistochemical assay. Ninety-six consecutive cases of fibroepithelial breast tumors were fixed in formalin, routinely processed, and embedded in paraffin wax. Sections $(3 \mu \mathrm{m})$ were mounted on silanized slides and left to dry overnight at $56^{\circ} \mathrm{C}$. The next day, the slides were dewaxed in xylene, rehydrated in graded alcohol and washed with water. Antigen retrieval was performed using a pressure cooker (Eterna Nigro $^{\mathrm{TM}}$, São Paulo, Brazil) and $10 \mathrm{mM}$ citrate buffer (pH 6.0) as described elsewhere (22). Samples were quenched with $6 \%$ hydrogen peroxide and incubated overnight at $4{ }^{\circ} \mathrm{C}$ with polyclonal rabbit anti-human CD117/c-kit (Dako Cytomation A/S, Denmark, Glostrup; cat no. A4502) diluted 1:6000 in phosphate-buffered saline (PBS) with $1 \%$ bovine serum albumin as an antibody diluent.

The following day, the slides were rinsed with PBS and incubated for $30 \mathrm{~min}$ at $37^{\circ} \mathrm{C}$ with the secondary antibody, biotinylated goat anti-mouse/rabbit immunoglobulin diluted 1:200. They were then rinsed again with PBS and incubated for $30 \mathrm{~min}$ at $37^{\circ} \mathrm{C}$ with streptavidin-biotinylated-peroxidase complex (Duet mouse/rabbit HRP, Dako Cytomation A/S; cat no. 0492) diluted 1:200. Finally, the slides were developed using $0.06 \%$ DAB as chromogen with $0.06 \%$ hydrogen peroxide, and counterstained with Harris' hematoxylin.

A second protocol of analysis was also performed using Tris-EDTA (ethylenediaminetetraacetic) buffer ( $\mathrm{pH}$ 8.0) as the heat-induced target retrieval solution and the primary antibody, diluted 1:5000.

Positive and negative control slides were included. For the negative control, the primary antibody was omitted. The positive control was a known case of gastrointestinal stromal tumor. A slide was considered positive when $>10 \%$ of the cells analyzed exhibited golden-brown staining. Staining was located in the cytoplasmic area in epithelial cells and was weakly evident in the cytoplasm and membrane of stromal cells.

Statistical analysis. Results were presented as descriptive frequencies when they were not suitable for statistical analysis. The $\chi^{2}$ and Student's t-tests were applied, when appropriate, using the Statistical Package for Social Sciences (SPSS) computer software.

\section{Results}

The surgical pathology reports were reviewed by two pathologists (F.A.S. and A.F.L.). FAs were denoted as classical (13) and juvenile (10), and the 70 PTs were classified according to standard criteria (stromal cellularity, atypia, stromal overgrowth, mitotic amount and category of borders) as 45 PTB, 17 PTBL, and 8 PTM samples. Expression of c-kit in stromal and epithelial cells was analyzed separately. A minimum of two large $(>1 \mathrm{~cm} \times 0.5 \mathrm{~cm})$ sections from each tumor was analyzed, containing representative stromal and epithelial components.

Stromal component. Among all the tumors, only two cases of PTBL contained stromal cells positive for c-kit expression. In all other benign PTs and FAs, fibroblasts were completely negative for c-kit expression. PTMs also showed no expression ( $<1 \%$ of fibroblasts) in the malignant stromal component. The same results were obtained when the immunoassay was repeated using pre-heated antigen retrieval. There was no particular morphological feature in the two positive cases compared to the other fibroepithelial lesions.

Epithelial component. The glandular component was more commonly positive for c-kit. Reactive cells showed a diffuse staining in the cytoplasm that was moderately intense and comparable to normal breast epithelial expression. In 38 of the 96 tumors studied, the ductal cells were reactive to c-kit antibody (39\%). These included 20 FAs (10 regular, 10 juvenile) and 18 PTs (11 PTBs and 8 PTBLs). However, in the remaining 58 tumors, the epithelial cells were completely negative. These included 6 FAs (4 regular, 2 juvenile), all 8 PTMs, 34 PTBs and 10 PTBLs. Considering both components together, 58 cases were totally negative and 36 exhibited c-kit expression restricted to the epithelial cells. Only two cases exhibited c-kit expression in both the glandular and stromal cells (Table I).

The two positive cases had $>10 \%$ positive fibroblasts scattered among the negative cells. In the most positive case, distribution of positive stromal cells was at most 40-50\%. Although these cases expressed the c-kit protein in a larger number $(>10 \%)$ of fibroblasts, the pattern was not of the large strong staining type commonly observed in GISTs. The majority of other cases did not show any reactivity at all. Myofibroblasts and endothelial cells were also negative for the protein.

In the epithelial cells, c-kit expression was assessed separately, and proved to be more common: 38 of 96 cases were positive for it. Usually, the intensity of staining in the epithelial cells was weaker than in normal tissue, and more frequently at 
Table I. Morphological diagnosis and c-kit expression in the stromal and epithelial components of fibroepithelial breast tumors.

\begin{tabular}{lccr}
\hline $\begin{array}{l}\text { Type of } \\
\text { tumor }\end{array}$ & $\begin{array}{c}\text { c-kit in } \\
\text { epithelial cells }\end{array}$ & $\begin{array}{c}\text { c-kit in } \\
\text { stromal cells }\end{array}$ & $\begin{array}{c}\text { Total } \\
\text { No. }\end{array}$ \\
\hline FA & $10(71.4 \%)$ & 0 & 14 \\
FAJ & $10(83.3 \%)$ & 0 & 12 \\
PTB & $11(24.4 \%)$ & 0 & 45 \\
PTBL & $7(41.1 \%)$ & 2 & 17 \\
PTM & 0 & 0 & 8 \\
Total & $38(39.5 \%)$ & $2(2.08 \%)$ & 96 \\
\hline
\end{tabular}

FA, fibroadenomas; FAJ, juvenile fibroadenomas; PTB, phyllodes tumors benign; PTBL, phyllodes tumors borderline; PTM, phyllodes tumors malignant.

the lobular unit rather than the ductal elements. Expression of c-kit in the two components of the two positive stromal cases did agree in terms of the presence of reactivity in the epithelial cells. In two cases, FA exhibited focal areas of typical (one case) and atypical (one case) epithelial hyperplasia, and focal adenosis was present or associated with the lesion in the other five cases, all of which were positive for c-kit. Older and atrophic lesions were generally totally negative; the more preserved the epithelial component, the more positive the tumor.

When c-kit expression in the epithelial cells was compared within the five subgroups of tumors, an evident correlation to diagnosis $(\mathrm{p}=0.0001)$ was found. While FAs showed a high frequency of staining (71-83\%), in PTBs epithelial cells were positive in only $24.4 \%$ of cases. There was an inversion of positivity between FAs and PTBs. c-kit staining in epithelial cells did not differ among juvenile and regular FAs, but among the PTs there was a marginal association $(\mathrm{p}=0.6522)$.

Stromal expression was not frequent enough to allow for any statistical correlation.

\section{Discussion}

Recently, the expression of c-kit in stromal tumors has attracted the interest of oncologists. The c-kit gene encodes a receptor tyrosine kinase that is differentially expressed in gastrointestinal stromal tumors (GISTs), but not in other stromal neoplasms, such as smooth muscle and neural tumors. A novel chemotherapeutic agent containing STI571, which is an active inhibitor of KIT tyrosine kinase activity, enables treatment of these tumors after surgery (14), and the identification of other possible targets of STI571 therapy is very appealing. However, the protein expression profile of stromal tumors appears to be very heterogeneous, and according to other studies reported in the literature $(17,19,21)$, few human stromal tumors express c-kit at the clinically relevant levels found in GISTs. Hornick and Fletcher (23) analyzed a wide range of stromal tumors and found staining for KIT in only a small percentage of soft tissue tumors. Their study included as many as 40 leyomyosarcomas, 25 rhabdomyosarcomas and 30 dermatofibrosarcomas protuberens, with no positive results. Tumors reactive for c-kit included 5 of 20 angiosarcomas, 4 of 20 Ewing sarcomas and 3 of 5 schwannomas. Also of interest is their reported weak pattern of reactivity in most positive cases, in contrast to the typically strong positivity commonly found in GISTs. In breast oncology, phyllodes tumors (PTs) are the most likely stromal tumors to be treatable with STI571 therapy, yet few studies on the expression of c-kit in these tumors have been conducted (17,19-21).

In the present study, c-kit expression analysis was performed in a series of malignant (PTM), borderline (PTBL) and benign (PTB) PTs, with a special interest in stromal overexpression. In order to better understand the relation of c-kit expression with stromal/epithelial overgrowth, several fibroadenomas (FAs) were included in this series. Reports of c-kit expression in FA are scarce. Forty examples of FA were studied by Tsuura et al, with little discussion of the distribution and results (24). As well, Ko et al (15) examined 15 cases, but the discussion of epithelial and stromal components and their reaction to c-kit was limited.

The two components of fibroepithelial neoplasms must be addressed separately. In this study, c-kit staining was found in the epithelium of a considerable percentage of FA cases. Moreover, epithelial staining was found in $30 \%$ of PTBs, suggesting that a subset of PTBs may have a phenotypic pattern more similar to that of FAs. It seems, based on the distribution of reactivity, that c-kit reactivity is somehow a 'normal cell' feature, progressively lost during fibroepithelial carcinogenesis. On the other hand, $20 \%$ of FA cases did not exhibit c-kit staining in the epithelia or the stroma. Positive cases of FA do not differ clinically from negative ones during evolution. The reason why glandular cells, which commonly express c-kit in normal breast epithelium, lose this capacity in seemingly benign lesions such as fibroadenomas is presently unclear, but this raises important questions as to the state of differentiation of the glandular cells. Further analysis of such a loss of protein expression could be of interest in hyperplasic lesions, as the majority of PTs are histologically abnormal (up to $60 \%$ have epithelial hyperplasia) and have been demonstrated to have allelic imbalance in the epithelium (25). The loss of c-kit expression may be a reflection of decreasing differentiation.

The role of c-kit in ductal epithelia remains to be elucidated, and future investigation of the relationship of its expression with cell metabolism is warranted. However, it appears that the environment within a fibroepithelial neoplasm becomes increasingly hazardous to ductal cells. The more irregular and malignant, the more compromised the cell machinery becomes. This hypothesis is not in accordance with the fact that many ductal carcinomas continue to express c-kit and, more specifically, that c-kit expression is pointed as one specific feature to basal-like carcinomas. Basal-like ductal carcinomas are usually high grade ER-negative tumors (26). It would be of interest to verify whether basal-cell carcinomas contain stromal cells with any distinct features. There may be commonalities between basal-cell carcinomas and fibroepithelial neoplasms with a poor prognosis.

Regarding the stromal component, a consistent loss of c-kit in the fibroepithelial tumors that did not appear to be closely 
Table II. Summary of key results of the studies about c-kit expression in fibroepithelial breast tumors in the literature.

\begin{tabular}{|c|c|c|c|c|c|c|}
\hline Author/(Refs.) & Year & $\begin{array}{c}\text { Total no. } \\
\text { FA }\end{array}$ & $\begin{array}{c}\text { Total no. } \\
\text { PT }\end{array}$ & $\begin{array}{c}\text { Epithelial } \\
\text { expression }\end{array}$ & $\begin{array}{c}\text { Stromal } \\
\text { expression }\end{array}$ & Method \\
\hline Chen et al (20) & 2000 & -- & $\begin{array}{c}19 \\
7 \mathrm{~B}\end{array}$ & NR & $\begin{array}{c}10 \\
1\end{array}$ & $\mathrm{IH}$ \\
\hline Tsuura et al (24) & 2002 & 50 & 16 & $\begin{array}{l}40 \\
15\end{array}$ & $\begin{array}{l}\text { NR } \\
\text { NR }\end{array}$ & $\mathrm{IH}+$ in situ $\mathrm{H}$ \\
\hline Ko et al (15) & 2003 & 15 & $1 \mathrm{~B}$ & $\begin{array}{l}15 \\
1 ?\end{array}$ & NR & $\mathrm{IH}$ \\
\hline Sawyer et al (21) & 2003 & -- & $\begin{array}{c}30 \\
20 \mathrm{~B} \\
10 \mathrm{M}\end{array}$ & NR & $\begin{array}{c}6 \\
1 \\
5 \\
1 / 10 \mathrm{M}\end{array}$ & $\begin{array}{c}\text { IH } \\
\text { PCR }\end{array}$ \\
\hline Tse et al (29) & 2004 & -- & $\begin{array}{c}179 \\
101 \mathrm{~B} \\
50 \mathrm{BL} \\
28 \mathrm{M}\end{array}$ & NR & $\begin{array}{l}17 \\
12 \\
13\end{array}$ & IH \\
\hline Tan et al (28) & 2005 & -- & $\begin{array}{c}255 \\
206 \mathrm{~B} \\
43 \mathrm{BL} \\
6 \mathrm{M}\end{array}$ & $\begin{array}{c}139 \\
24 \\
12\end{array}$ & $\begin{array}{l}7 \\
4 \\
6\end{array}$ & IH tissue array \\
\hline Carvalho et al (27) & 2004 & & $\begin{array}{c}19 \\
13 \mathrm{~B} \\
6 \mathrm{M}\end{array}$ & $\begin{array}{l}9 \\
4\end{array}$ & $\begin{array}{c}6 \\
6 \\
6 \mathrm{~B} \\
2 \mathrm{~B}\end{array}$ & SEQ \\
\hline
\end{tabular}

FA, fibroadenoma; PT, phyllodes tumor; M, malignant; B, benign; BL, borderline; IH, immunohistochemistry; in situ H, in situ hybridization; PCR, polymerase chain reaction; SEQ, direct sequencing; NR, not recorded.

related to malignancy was found. Conflicting results have been presented by some authors, who identified a higher incidence of c-kit reactivity in the stromal component $(20,27)$. Table II lists the results of c-kit expression in fibroepithelial tumors currently available in the literature. Moreover, when polymerase chain reaction (PCR) was used for analysis, the separate scraping of each component from slides was seldom performed. In some cases, mutations in the c-kit gene were identified, although in two cases epithelial expression was also reported. The same rate of reactivity could not be identified here. Indeed, previous studies have found that c-kit expression in PTs is variable. However, few studies have been able to identify reactivity specifically in stromal cells. It seems that each component of the tumor reacts variably, as Sawyer et al (16) demonstrated when observing the different etiology of each component of PTs. Tan et al studied the largest series of PTs in the literature, analyzing c-kit expression by the tissue array method, and identified only 17 cases with stromal positivity out of 355 (28).

Discrepancies between studies can be attributed to differences in the techniques or the particular antibodies used. As well, certain studies used antigen retrieval, while others did not apply this step in the immunohistochemical assay. Moreover, not all cases exhibiting overexpression of c-kit demonstrated DNA alterations (27). Cleary, the immunohistochemical identification and interpretation of c-kit protein expression in PTs requires further investigation before it can be effectively used for treatment and as a prognostic indicator. For the time being, careful histological evaluation, along with adequate tumor sampling, appears to provide the most clinically relevant and useful information (4).

The expression of c-kit is not a major event in breast fibroepithelial tumors, and should not be a target of therapeutic approaches until the mechanism that leads to the epithelial accumulation of c-kit has been elucidated.

\section{References}

1. Guerrero MA, Ballard BR and Grau AM: Malignant phyllodes tumor of the breast: review of the literature and case report of stromal overgrowth. Surg Oncol 12: 27-37, 2003.

2. Rowel MD, Perry RR, Hsiu JG and Barranco SC: Phyllodes tumors. Am J Surg 165: 376-379, 1993.

3. Rosen PP: Fibroepithelial neoplasms. In: Rosen's Breast Pathology. Rosen PP (ed). Lippincott-Raven Publishers, Philadelphia, pp143-175, 1996. 
4. Palmer ML, De Risi DC, Pelikan A, et al: Treatment options and recurrence potential for cystosarcoma phyllodes. Surg Gynecol Obstet 170: 193-196, 1990.

5. Feakins RM, Mulcahy HE, Nickols CD and Wells CA: p53 expression in phyllodes tumours is associated with histological features of malignancy but does not predict outcome. Histopathology 35: 162-169, 1999.

6. Kuenen-Boumeester V, Henzen-Logmans SC, Timmermans MM, et al: Altered expression of $\mathrm{p} 53$ and its regulated proteins in phyllodes tumours of the breast. J Pathol 189: 169-175, 1999.

7. Keelan PA, Myers JL, Wold LE, Katzmann JA and Gibney DJ: Phyllodes tumor: clinicopathologic review of 60 patients and flow cytometric analysis in 30 patients. Hum Pathol 23: 1048-1054, 1992.

8. Kleer CG, Giordano TJ, Braun T and Oberman HA: Pathologic, immunohistochemical, and molecular features of benign and malignant phyllodes tumors of the breast. Mod Pathol 14: 185-190, 2001.

9. Layfield LJ, Hart J, Neuwirth H, Bohman R, Trumbull WE and Giuliano AE: Relation between DNA ploidy and the clinical behavior of phyllodes tumors. Cancer 64: 1486-1489, 1989.

10. Hirota S, Isozaki K, Moriyama Y, et al: Gain-of-function mutations of c-kit in human gastrointestinal tumors. Science 279: 577-580, 1998.

11.Yaden Y, Kuang WJ, Yang-Feng T, et al: Human protooncogene c-KIT: a new cell surface receptor tyrosine kinase for an unidentified ligand. EMBO J 6: 3341-3351, 1987.

12. Miettinen M and Lasota J: Gastrointestinal stromal tumors definition, clinical, histological immunohistochemical, and molecular genetic features and differential diagnosis. Virchows Arch 438: 1-12, 2001.

13. Zsebo KM, Williams DA, Geissler EN, et al: Stem cell factor is encoded at the SI locus of the mouse and is the ligand for the c-kit tyrosine kinase receptor. Cell 63: 213-224, 1990.

14. Debiec-Rychter M, Dumez H, Judson I, et al: Use of c-KIT/ PDGFRA mutational analysis to predict the clinical response to imatinib in patients with advanced gastrointestinal stromal tumours entered on phase I and II studies of the EORTC Soft Tissue and Bone Sarcoma Group. Eur J Cancer 40: 689-695, 2004.

15. Ko CD, Kim JS, Ko BG, et al: The meaning of the c-kit protooncogene product in malignant transformation in human mammary epithelium. Clin Exp Metastasis 20: 593-597, 2003.

16. Sawyer EJ, Hanby AM, Ellis P, et al: Molecular analysis of phyllodes tumors reveals distinct changes in the epithelial and stromal components. Am J Pathol 156: 1093-1098, 2000.
17. Chui X, Egami H, Yamashita J, Kurizaki T, et al: Immunohistochemical expression of the c-kit proto-oncogene product in human malignant and non-malignant breast tissues. Br J Cancer 73: 1233-1236, 1996.

18. Natali PG, Nicotra MR, Sures I, Mottolese M, Botti C and Ullrich A: Breast cancer is associated with loss of the c-kit oncogene product. Int J Cancer 52: 713-717, 1992.

19. Palmu S, Söderström KO, Quazi K, Isola J and Salminen E: Expression of C-KIT and HER-2 tyrosine kinase receptors in poor-prognosis breast cancer. Anticancer Res 22: 411-414, 2002.

20. Chen CM, Chen CJ, Chang CL, Shyu JS, Hsieh HF and Harn HJ: CD34, CD117, and actin expression in phyllodes tumor of the breast. J Surg Res 94: 84-91, 2000.

21. Sawyer EJ, Poulsom R, Hunt FT, et al: Malignant phyllodes tumours show stromal overexpression of c-myc and c-kit. J Pathol 200: 59-64, 2003.

22. Zidan A, Christie Brown JS, Peston D and Shousha S: Oestrogen and progesterone receptor assessment in core biopsy specimens of breast carcinoma. J Clin Pathol 50: 27-29, 1997.

23. Hornick JL and Fletcher CD: Immunohistochemical staining for KIT (CD117) in soft tissue sarcomas is very limited in distribution. Am J Clin Pathol 117: 188-193, 2002.

24. Tsuura Y, Suzuki T, Honma K and Sano M: Expression of c-kit protein in proliferative lesions of human breast: sexual difference and close association with phosphotyrosine status. J Cancer Res Clin Oncol 128: 239-246, 2002.

25. Wang ZC, Buraimoh A, Iglehart JD and Richardson AL: Genome-wide analysis for loss of heterozygosity in primary and recurrent phyllodes tumor and fibroadenoma of breast using single nucleotide polymorphism arrays. Breast Cancer Res Treat 97: 301-309, 2006.

26. Jumppanen M, Gruvberger-Saal S, Kauraniemi P, et al: Basallike phenotype is not associated with patient survival in estrogenreceptor-negative breast cancers. Breast Cancer Res 9: R16, 2007.

27. Carvalho S, Silva AO, Milanezi F, et al: c-KIT and PDGFRA in breast phyllodes tumours: overexpression without mutations? J Clin Pathol 57: 1075-1079, 2004.

28. Tan PH, Jayabaskar T, Yip G, et al: p53 and c-kit (CD117) protein expression as prognostic indicators in breast phyllodes tumors: a tissue microarray study. Mod Pathol 18: 1527-1534, 2005.

29. Tse GM, Lui PC, Lee CS, et al: Stromal expression of vascular endothelial growth factor correlates with tumor grade and microvessel density in mammary phyllodes tumors: a multi-center study of 185 cases. Hum Pathol 35: 1053-1057, 2004. 